\title{
Failure Behavior and Damage Mechanism of Acrylic Polyurethane Coating in Tropical Marine Atmospheric Environment
}

\author{
Zhao Li ${ }^{1}$, Jie Liu ${ }^{1, *}$, Shaohua Xing ${ }^{2}$, Lunwu Zhang ${ }^{3}$, Zhonghai Lu ${ }^{1}$, Peiqing Zhang ${ }^{1}$ \\ ${ }^{1}$ College of Chemistry and Chemical Engineering, Yantai University, Yantai 264005, P. R. China \\ ${ }^{2}$ State Key Laboratory for Marine Corrosion and Protection, Luoyang Ship Material Research Institute \\ (LSMRI), Qingdao 266237, P. R. China \\ ${ }^{3}$ Southwest Technology and Engineering Research Institute, Chongqing 400039, P. R. China \\ *E-mail: liujie6573@163.com
}

doi: $10.20964 / 2020.03 .39$

Received: 19 July 2019 / Accepted: 16 September 2019 / Published: 10 February 2020

\begin{abstract}
Acrylic polyurethane coating was exposed to the tropical marine atmospheric environment for 24 months, and the physical, chemical and protective properties of the coating were investigated. The results demonstrated that the appearance, adhesion and protective property of the coating were degraded rapidly in the early exposure stage, and then changed slowly in the late exposure stage. During the filed exposure test, the ultraviolet irradiation was a major contributor to polyurethane chain scission of the coating, and the chain scission was mainly characterized by the rupture of $\mathrm{C}-\mathrm{N}$ bonds. Moreover, the thermal stability of the coating was less affected by the tropical marine atmospheric environment.
\end{abstract}

Keywords: marine atmosphere; acrylic polyurethane coating; physical changes; chemical structures; EIS

\section{FULL TEXT}

(C) 2020 The Authors. Published by ESG (www.electrochemsci.org). This article is an open access article distributed under the terms and conditions of the Creative Commons Attribution license (http://creativecommons.org/licenses/by/4.0/). 